\title{
Identifying barriers and finding solutions to implement best practices for cancer surgery at Maputo Central Hospital, Mozambique
}

\author{
Atílio Morais ${ }^{1}$, Matchecane Cossa ${ }^{1}$, Adriano Tivane ${ }^{1}$, Jotamo Come ${ }^{2}$, Volodimir Venetsky ${ }^{2}$, Fernando Torres ${ }^{2}$, Victor Pacheco ${ }^{3}$, \\ Miguel Reyes ${ }^{3}$, Germano Pires ${ }^{4}$, Mariana Peyroteo ${ }^{5}$, Satish Tulsidas ${ }^{6}$, Ellen Baker ${ }^{7}$, Moshin Sidat ${ }^{8,9}$, Maria do Rosário O Martins ${ }^{9}$, \\ Lúcio Lara Santos $5,10,11$
}

\author{
${ }^{1}$ Thoracic Surgery, Surgical Department, Maputo Central Hospital, Av Agostinho Neto $n^{\circ} 164$, Maputo 1164, Mozambique \\ ${ }^{2}$ Breast Surgery, Surgical Department, Maputo Central Hospital, Av Agostinho Neto $n^{\circ} 164$, Maputo 1164, Mozambique \\ ${ }^{3}$ Colorectal Surgery, Surgical Department, Maputo Central Hospital, Av Agostinho Neto n 164, Maputo 1164, Mozambique \\ ${ }^{4}$ Heath National Institute, Av Eduardo Mondlane, Maputo 264, Mozambique \\ ${ }^{5}$ Surgical Oncology Department, Portuguese Institute of Oncology, Dr António Bernardino de Almeida Street, Porto 4200-072, Portugal \\ ${ }^{6}$ Medical Oncology Department, Maputo Central Hospital, Av Agostinho Neto n 164, Maputo 1164, Mozambique \\ ${ }^{7}$ UT MD Anderson Cancer Center, 1515 Holcombe Blvd, Houston, TX 77030, USA \\ ${ }^{8}$ Department of Community Health, University Eduardo Mondlane, Av Julius Nyerere, Maputo 257, Mozambique \\ ${ }^{9} \mathrm{Global}$ Health and Tropical Medicine, Institute of Hygiene and Tropical Medicine, Universidade Nova de Lisboa, Junqueira Street 100, Lisboa 1349-008 \\ Portugal \\ ${ }^{10}$ Experimental Pathology and Therapeutics Research Group, Surgical Oncology Department, Portuguese Institute of Oncology, Dr António Bernardino de \\ Almeida Street, Porto 4200-072, Portugal \\ ${ }^{11}$ ONCOCIR—Education and Care in Oncology—Lusophone Africa, Quires Street 168, Moreira da Maia 4470-643, Portugal
}

Correspondence to: Lúcio Lara Santos. Email: Ilarasantos@gmail.com

\begin{abstract}
Purpose: The aim of this study was to assess the surgical resources and surgical oncology team skills at the Surgical Department of Maputo Central Hospital (MCH) in Mozambique in order to define an educational program to support surgical oncology practice.

Methods: From January 2017 to December 2017, a general evaluation of the resources of MCH was carried out, as well as its offerings in oncological care in different services. Data were obtained by reviewing documents, visiting surgical services and interviewing keyinformants and others informally. In addition, a group of seven surgeons of the Surgical Department of $\mathrm{MCH}$ answered a questionnaire about the quality of the cancer units (The Cancer Units Assessment Checklist for low- or middle-income African countries). Subsequently, surgical, anaesthesiology and intensive care facilities were evaluated according to the Portuguese-speaking African Countries Assessment of Surgical Oncology Capacity Survey (PSAC-Surgery). All the data were triangulated in order to identify gaps, develop an action plan and define an educational program.
\end{abstract}

Published: 23/10/2018

Received: 16/03/2018

ecancer 2018, 12:878 https://doi.org/10.3332/ecancer.2018.878

Copyright: $\odot$ the authors; licensee ecancermedicalscience. This is an Open Access article distributed under the terms of the Creative Commons Attribution License (http://creativecommons.org/licenses/by/3.0), which permits unrestricted use, distribution, and reproduction in any medium, provided the original work is properly cited. 
Results: Breast, oesophagus and colorectal cancers were the most commonly treated neoplasms in $\mathrm{MCH}$. A range of technical and resource needs as well as the gaps in knowledge and skills were identified. All surgeons recognised the need to create a training program in oncology at the undergraduate level, specific training for residents and continuing oncological education for general surgeons to improve the practice of surgical oncology. It was evident that all these interventions needed to be formalised, appropriately certified and count for professional career progression. Based on the local epidemiological data and on these study findings, oncology education programs were developed for surgeons.

Conclusions: The findings of this study contributed to the development of an educational program in surgical oncology, considered essential to the training of surgeons at $\mathrm{MCH}$. The cancer educational programs and the mobilisation of adequate resources will ensure the provision of adequate surgical oncology treatments for $\mathrm{MCH}$. The training requirements should be tailored to suit the local needs based on the most prevalent malignancies diagnosed in the region. In our view, this methodology may apply to other countries with similar realities in the formation of surgical oncologists.

Keywords: training, surgical oncology, curriculum development, Mozambique

\section{Introduction}

Cancer is a major public health problem in Sub-Saharan Africa because of population aging, as well as increased prevalence of key risk factors [1]. The resources available for cancer control are less than adequate in Africa; therefore, standardised cancer treatment for lowand middle-income African countries (LMIACs) is still a major concern and surgery plays an important role in the diagnosis, staging and treatment of cancer [2,3]. In most LMIACs, as Mozambique, surgery remains the only locoregional treatment and represents the best hope for the cure, thus a careful evaluation of surgical team skills is critical to improving cancer management [4]. In addition, the quantity, quality and functionality of equipment and supplies, availability of running water and electricity, access to safe blood transfusion services, chemotherapy and radiation, the presence of postoperative facilities as well as the number, type and qualification of healthcare personnel should be included in the assessment of cancer surgery quality [4]. Noncommunicable diseases, including cancer, have been considered a major public health problem by the Ministry of Health of Mozambique since 2008 [5].

According to Lorenzoni et al [6], in males, the most common cancers are prostate, Kaposi sarcoma (KS), liver and oesophagus. In females, the most frequent cancers are cervix, breast, KS and oesophagus.

The report on human resources needed for cancer control in low- and middle-income countries, performed by the National Cancer Institute suggested that surgical oncologists, medical oncologists and radiation oncologists are an unmet need in Mozambique. In addition, support staffs such as onco-pharmacists, pharmacy technicians, oncology nurses and palliative care specialists are also needed. Recently, an article evaluating the cancer plans for Mozambique the authors revealed that there are only seven oncologists in the country and no oncological surgeons $[7,8]$. Thus, an educational cancer program is crucial to existing surgical teams and medical students.According to Snyder et al [9], $14 \%$ of the causes of death in the Maputo Central Hospital (MCH) surgery department are oncological diseases and neoplasms accounted for $9 \%$ of all surgical discharge diagnoses [9]. The cancer registry of the $\mathrm{MCH}$ in 2015-16 pointed out that the malignant tumours most often operated by general and thoracic surgery are breast, oesophageal and colorectal cancer [10].

In order to develop and implement a Cancer Education Program (CEP) and introduce best practices for cancer surgery at $\mathrm{MCH}, \mathrm{Mozambique}$, we assessed current surgical resources and surgical oncology skills.

\section{Methods}

This cross-sectional study was conducted between January 2017 and December 2017 in MCH, a tertiary level hospital in Mozambique. An evaluation of the general capacity of $\mathrm{MCH}$ and its offer in oncological care in the different services was done through documental analysis, visits to the services and informal interviews to the providers of oncological care in those services. In addition, a questionnaire was administered to the seven general surgeons of the surgical Department of $\mathrm{MCH}$, who have the main role in the surgical treatment of the most frequent types of cancer, namely, breast (three surgeons), colorectal (two surgeons) and oesophageal cancer (two surgeons). 
The questionnaire used was the cancer units assessment checklist for low- or middle-income African countries [11]. Subsequently, surgical, anaesthesiology and intensive-care facilities were evaluated according to the Portuguese-speaking African Countries Assessment for Surgical Oncology Capacity Survey (PSAC-Surgery) in order to identify gaps.

This second instrument assesses the capacity of the hospital to perform surgical oncological procedures; infrastructures available; specific resources to perform breast, oesophageal and colorectal cancer surgery; workforce available, and the number of surgical oncology procedures per year.

The institutions that train health professionals in Mozambique were also evaluated in order to understand the formative capacity and the potential integration of a CEP in their curriculum.

After the visits, interviews, documental analysis and questionnaires assessment, the main needs in general oncology and surgical oncology were identified, in particular, for residents and fellows in general surgery. Moreover, a set of recommendations for the training of general surgeons at $\mathrm{MCH}$ Surgical Department were also suggested.

Questionnaires were collected on paper and the data were entered into an electronic database. Descriptive statistics were performed. This study was approved for the Mozambican National Bioethical Committee.

\section{Results}

$\mathrm{MCH}$, a tertiary unit level (1500 beds), is the referral centre for all of the complex surgical care in the country. $\mathrm{MCH}$ provides a complete emergency service with advanced diagnostic capacities, inpatient wards for complex medical and surgical care (325 beds in the surgical unit), three fully equipped operating rooms, a fully equipped delivery room, three recovery rooms, an intensive-care unit, two high dependency care units and rehabilitation therapy facilities. The centre is also equipped with respirators, oxygen supply devices, intravenous fluids, blood products, basic microbiology equipment, the main pharmaceuticals (anaesthetics, analgesics, antibiotics) and the main surgical materials (drapes, gowns, dressings, gloves) as well as other consumables (disposable equipment and devices).

Human resources for health at $\mathrm{MCH}$ include: nurses -700 , operating room nurses-30, anaesthetists nurses-15, anaesthesiologists - 20, general physicians - 125, obstetricians/gynaecologists-20, general surgeons - 10, orthopaedic surgeons - 7, pharmacy assistants - 40, pharmacists -10 , radiology technicians -12 , radiologists -3 , physiotherapists -2 , neurosurgeons -5 , thoracic surgeons -3 , reconstructive surgeons -3 , urologists -4 , medical oncologists -3 , radio-oncologist -1 , medical physics -3 , gastroenterologists -4 and pathologists-10.

The first questionnaire was fulfilled by seven surgeons. Cancer diagnosis pitfalls were related with fragile imaging resources and low capacity to perform biopsies guides per image. The specific needs to properly diagnose and treat the most common tumours are summarised in Table 1.

For treatment capacities, the following needs were identified: existence of a safe oncology pharmacy with access to essential oncology drugs according to the WHO list; the improvement of the day hospital facilities; to start the activity of the radiotherapy unit; to endow the surgical services with the missing resources and to produce guidelines to ensure good practice in oncology. Other needs include pre-rehabilitation programs for frail patients, rehabilitation and palliative care. At present, there are no surgeons with formal training and certification in surgical oncology.

All surgeons recognised the need to create a training program in oncology at the undergraduate level. Table 2 shows the training capacity of health professionals in Mozambique where this training should take place. Moreover, a specific training for residents and fellows (wherever possible with practical training in high workload centres) and continuing oncological education for general surgeons to improve the practice of surgical oncology was also recommended (Table 3). Surgeons also underlined that their participation in multidisciplinary decision-making meetings (locally known as the tumour Commission) is infrequent; they also stressed the need to improve the oncological knowledge about the most frequent tumours, scientific research and how to strength external collaborations.

Since the most frequently diagnosed tumours surgically treated at $\mathrm{MCH}$ are breast, oesophageal and colorectal cancer and based on the gaps mentioned by the seven surgeons, a Global Curriculum in Surgical Oncology was elaborated and will be tested at the MCH (Table 4) [12]. 
Table 1. Specific resources lacking to perform breast, colorectal and esophageal cancer surgical treatment.

\begin{tabular}{|l|l|l|l|}
\hline & \multicolumn{1}{|c|}{ Breast cancer } & \multicolumn{1}{|c|}{ Colorectal cancer } \\
\hline Diagnostic & $\begin{array}{l}\text { imaging resources and to perform core needle biopsy of } \\
\text { the breast }\end{array}$ & Rigid sigmoidoscope & Imaging resources \\
\hline \multirow{2}{*}{ Surgery } & Patent Blue V for sentinel lymph node biopsy & Bookwalter retractor system & Surgical Clips and Clamps \\
\cline { 2 - 4 } & $\begin{array}{l}\text { Fluorescence navigation with indocyanine green for } \\
\text { detecting sentinel lymph nodes }\end{array}$ & Saint Mark's pelvic retractor & Circular and linear staplers \\
\cline { 2 - 4 } & Surgical clips & Surgical stapler for rectum & $\begin{array}{l}\text { Harmonic scalpel } \\
\text { consumables }\end{array}$ \\
\hline Post-operative care & Aspiration drainage & $\begin{array}{l}\text { Provide information and advice } \\
\text { on diet to stoma patients }\end{array}$ & Oesophageal stents \\
\hline
\end{tabular}

Table 2. Training capacity of Mozambique in surgery, anaesthetist and nurses.

\begin{tabular}{|c|c|c|c|c|c|c|c|}
\hline \multirow[t]{2}{*}{$\begin{array}{c}\text { Health } \\
\text { professional }\end{array}$} & \multirow[t]{2}{*}{$\begin{array}{c}\text { Academic } \\
\text { level (degree) }\end{array}$} & \multirow{2}{*}{$\begin{array}{l}\text { Years of duration } \\
\text { (academic degree, } \\
\text { training + residency) }\end{array}$} & \multirow{2}{*}{$\begin{array}{c}\text { Rotation in } \\
\text { oncology during } \\
\text { studies }\end{array}$} & \multirow{2}{*}{$\begin{array}{c}\text { Number of } \\
\text { certifying universities/ } \\
\text { institutions }\end{array}$} & \multirow{2}{*}{$\begin{array}{l}\text { Number } \\
\text { graduates } \\
\text { per year }\end{array}$} & \multicolumn{2}{|c|}{$\begin{array}{l}\text { Educational } \\
\text { institutions }\end{array}$} \\
\hline & & & & & & $\begin{array}{l}\text { Public } \\
\text { sector }\end{array}$ & $\begin{array}{l}\text { Private } \\
\text { sector }\end{array}$ \\
\hline Nurse & BSc & 3 years & No & 4 & 60 & 4 & 4 \\
\hline Nurse Anaesthetist & BSc, AN & $2+3$ years & No & 1 & 10 & 1 & \\
\hline $\begin{array}{l}\text { General } \\
\text { practitioner }\end{array}$ & MD & 6 years & Yes & 8 & 200 & 4 & 4 \\
\hline Anaesthetist & $\mathrm{MD}+\mathrm{R}$ & $6+5$ years & Yes & 1 & 3 & 1 & \\
\hline Gynaecologist & $M D+R$ & $6+5$ years & Yes & 1 & 5 & 1 & \\
\hline Orthopaedist & $M D+R$ & $6+4$ years & No & 1 & 3 & 1 & \\
\hline Urologist & $M D+R$ & $6+5$ years & Yes & 1 & 1 & 1 & \\
\hline General surgeon & $M D+R$ & $6+5$ years & Yes & 1 & 4 & 1 & \\
\hline Thoracic surgeon & $M D+R$ & $6+5$ years & Yes & 1 & 1 & 1 & \\
\hline Plastic Surgeon & $M D+R$ & $6+5$ years & Yes & 1 & 1 & 1 & \\
\hline
\end{tabular}

$\mathrm{BSc}=$ Bachelor of Science in Nursing; $\mathrm{AN}=$ Anaesthetic Nursing. $\mathrm{MD}=$ Medical Doctor graduation, $\mathrm{R}=$ Residency

*According to the Mozambican catalogue of higher education (www.mzformativa.com)

Table 3. MCH CEP (Modules).

\begin{tabular}{|l|l|l|}
\hline Undergraduate level & \multicolumn{1}{|c|}{ General surgery residents } & \multicolumn{1}{|c|}{ General surgeons $^{*}$} \\
\hline Basics of oncology & Basics of oncology & Breast cancer \\
\cline { 2 - 3 } & Breast cancer & Colorectal cancer \\
\cline { 2 - 3 } & Colorectal cancer & Oesophageal cancer \\
\cline { 2 - 3 } & Oesophageal cancer & Advanced surgical oncology training \\
\cline { 2 - 3 } & Surgical oncology fellowships &
\end{tabular}

${ }^{*}$ According their oncological field and surgical expertise 
Table 4. Modules and core content of the MCH CEP.

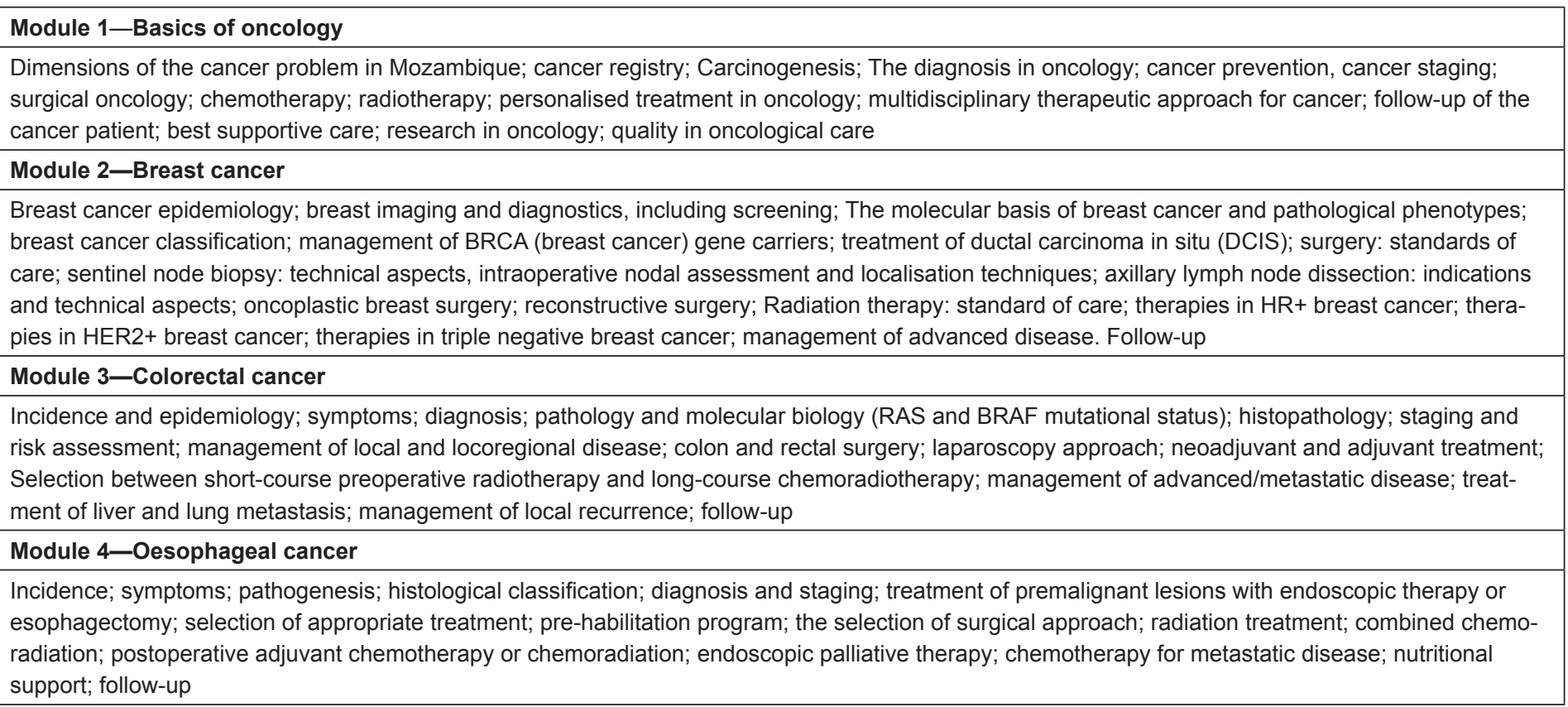

\section{Discussion}

$\mathrm{MCH}$, the referral centre for all complex surgical care in Mozambique, provides primary surgical care for its local population and is also a teaching hospital. In MCH, the top three solid tumours treated by general and thoracic surgery are breast, oesophageal and colorectal cancer.

This study was particularly helpful to define the global needs of cancer education at the national level and, in particular, at $\mathrm{MCH}$. The results from the first questionnaires revealed a shortage of both technical and material resources and skills/formative deficits. In addition, direct observation through the visit to operating rooms, intensive care and ward facilities was critical in order to identify existing resources and needs. Based on the second questionnaire results, it was possible to assess the needs for quality cancer surgery. We realised the current organisational level of cancer care, all human resources of $\mathrm{MCH}$ will be fundamental in the organisation of oncology but most of them, including de surgeons, need specific training. We agree that is also important and crucial to creating a training program in oncology at the undergraduate level. The challenge is how we can do it effectively, taking into account local realities.

The complex nature of cancer makes oncological surgeries highly technically demanding and, therefore, outcomes are improved when surgery is undertaken by experienced multidisciplinary teams of specialists at high-workload centres and with adequate resources [13].

Our results show that surgeons participate erratically in the multidisciplinary therapeutic decision meeting. Multidisciplinary programs provide many benefits for the physicians involved [14, 15]. The attendance of multiple specialists from each discipline in this type of meetings leads to dynamic discussion and learning opportunities for all, especially students and trainees [16]. Multidisciplinary team management is associated with improved outcomes after surgery for breast, colorectal and oesophageal cancer [17, 18].

Stefan et al [19] address the various areas of oncology in a very interesting article on education and training for the future in cancer research at the East African Regional Meeting. Unfortunately, in their work, the training of surgical oncologists was not discussed [19]. However, the College of Surgeons of East, Central and Southern Africa developed a fellowship in surgical oncology and the average length of time it takes to train surgical oncologist ranges from 11 to 17-19 years [20]. However, this training is long and does not cover the immediate needs of Mozambique. It is necessary to combine a formal training with a fast-track program (2 years). Thus, in order to improve the quality 
of care in $\mathrm{MCH}$, the creation of a comprehensive CEP to address the educational needs of medical students, interns, residents, fellows, nurses and allied health staff is crucial. However, cultural and university education differences of the Lusophone African countries must be taken into account. It is important that training in oncology and surgical oncology considers these differences.

Despite different interventions to train Mozambique oncologists involving Brazilian hospitals, the Calouste Gulbenkian foundation from Portugal, MD Anderson Cancer Center from USA and others, according to the respondents, there were no substantial changes in the practice of surgical oncology at $\mathrm{MCH}$. It seems clear that without integrating these training efforts into an official and formal CEP at different levels (namely, pre-graduate and continuing medical education), the results will continue to be fragile and these activities will be erratic [21, 22].

A surgical oncologist should possess in-depth knowledge of malignancies involving each specific disease site. Thus, our proposal takes into account local resources, the nosological profile, the critical actors on the ground and the need to first create a group of competent trainers who later disseminate oncology training in general and oncology surgery in particular.

We follow the recommendations of Are et al [12], regarding the training and certification of surgical oncologists, namely: The training period should be shortened, if possible. The training requirements can be tailored to suit the local needs based on the most prevalent malignancies diagnosed in the region. LMIACs can proactively partner with foreign countries that offer surgical oncology fellowships. Emphasis also needs to be placed on continuing medical education to remain abreast of the current standards of treatment. Training should include the basic principles of chemotherapy and other disciplines of oncology. Surgeons should also be equipped with knowledge on pain, palliative care in order to improve the quality of life for cancer patients [20].

In the definition of the contents suggested in our programme, we adopted the global curriculum in surgical oncology suggested by Are et al [12], the recommendations of Mozambican surgeons, but we prioritise the surgical treatment of the most prevalent malignancies in Mozambique, as had already been done in other Lusophone African countries with success [23].

As a whole, during the 2 years surgical oncology fellowship programme (during surgical residency), the clinical rotation includes: 12 months spent in the surgical oncology department of a high-volume centre, focusing on complex oesophageal and gastrointestinal malignancies, pancreatic and hepatobiliary malignancies, breast cancer, melanoma, head and neck cancer, bone and soft-tissue sarcoma and foregut malignancies; 1 month in a radiation therapy unit; 1 month in a pathology unit and 1 month in a medical oncology department. The remaining 9 months will be spent in Mozambique conducting oncological research activity.

For formal general and thoracic surgeons, $\mathrm{MCH}$ should offer advanced training opportunities in surgical oncology (3 months) who have before completed the basic oncology training program and are interested in an additional intensive experience in advanced surgical oncology related to their specific area, namely, breast cancer, colorectal or oesophageal cancer. In our view, this methodology may apply to other countries with similar realities, daily activity and difficulties encountered should become teaching and research issues in order to overcome them properly. Specific topics, such as assessment based on decision making on assignment as trusted professional activities, is probably a useful methodological option in this context [24].

Thus, the proposal of our study should be discussed by the country's health and university authorities and by the college of surgeons in order to integrate this Mozambican program for training surgical oncologists and then evaluate its effectiveness.

Similar programs should be implemented in other African countries, demonstrating their capacity to adapt to their specific reality and conditions. Those responsible for the training of surgical oncologists from countries with high resources should, according to the difficulties we have studied, develop specific and adapted courses that can be used as a complement of the training capacities of developing countries. For surgical oncology fellows in higher-resource settings specifically, the learning benefits of rotations in LMICs are even greater since they learn to deal with cancer patients at advanced stages or different cancer biology, in countries having fewer screening options, fewer imaging options, as well as limited perioperative care [25].

\section{Conclusions}

The findings of this study contributed to the development of an educational program in surgical oncology considered essential for the training of surgeons and residents of surgery at $\mathrm{MCH}$. Undergraduate medical training programmes should incorporate oncology education. 
Cancer education should fully integrate all healthcare professionals involved in cancer care. The educational cancer program and the mobilisation of adequate resources will ensure the provision of adequate surgical oncology treatments at $\mathrm{MCH}$. The training requirements should be tailored to suit the local needs based on the most prevalent malignancies diagnosed in the region. In our view, this methodology may apply to other countries with similar realities in the training of surgical oncologists.

\section{Conflicts of interest}

Ellen Baker is the director of Project ECHO, MD Anderson, USA.

For the other authors, there are no conflicts of interest to disclose and no financial or commercial relationships.

\section{Authors' contributions}

This study was conceptualised, designed and written by Atílio Morais and Lúcio Lara Santos. Acquisition of data was carried out by Atílio Morais, Adriano Tivane, Matchecane Cossa, Jotamo Come, Volodimir Venetsky, Fernando Torres, Victor Pacheco, Miguel Reyes, Germano Pires. Analysis and interpretation of data were done by Atílio Morais, Mariana Peyroteo and Lúcio Lara Santos. Ellen Baker, Satish Tulsidas, Maria Rosário Martins, Moshin Sidat and Lúcio Lara Santos revised the article for important intellectual content. All authors read and agreed to the final version of this manuscript. Atílio Morais and Lúcio Lara Santos equally contributed to this study.

\section{Acknowledgments}

We thank all of the health professionals of $\mathrm{MCH}$ who helped the authors to perceive the difficulties, the needs and pointed out solutions to develop better care in surgical oncology in this institution.

\section{Funding}

This investigation had no financial support.

\section{References}

1. Jemal A, Vineis P, and Bray F, et al (eds) (2014) The cancer atlas 2nd edn (Atlanta, GA: American Cancer Society) chapter 16, p 48

2. Stefan DC (2015) Cancer care in Africa: an overview of resources J Global Oncol 1 30-36 https://doi.org/10.1200/JGO.2015.000406

3. World Health Organization (2002) National cancer control programmes: policies and managerial guidelines (Geneva: World Health Organization) [ISBN 924154557 7]

4. Parham GP, Mwanahamuntu MH, and Hicks ML, et al (2016) Population-level scale-up of surgical oncology platforms in Africa, with a particular focus on women's cancer care The State of Oncology in Africa eds P Boyle, T Ngoma, and R Sullivan, et al (Lyon, France: iPRI Scientific Publication 4, iPRI) pp 69-83

5. Carvalho-Fumane JM (2016) Mozambique The State of Oncology in Africa eds P Boyle, T Ngoma, and R Sullivan, et al (iPRI Scientific Publication4, iPRI, Lyon, France) pp 416-424

6. Lorenzoni C, Vilajeliu A, and Carrilho C, et al (2015) Trends in cancer incidence in Maputo, Mozambique, 1991-2008 PLoS One 10(6) e0130469 https://doi.org/10.1371/journal.pone.0130469 PMCID: 4481529 
7. [https://rrp.cancer.gov/programsResources/lowlncome/mozambique.pdf] Date accessed: 21/08/18

8. Lorenzoni C, Oliveras L, and Vilajeliu A, et al (2018) Weak surveillance and policy attention to cancer in global health: the example of Mozambique BMJ Glob Health 3(2) e000654 https://doi.org/10.1136/bmjgh-2017-000654 PMID: 29607101 PMCID: 5873532

9. Snyder E, Amado V, and Jacobe M, et al (2015) General surgical services at an urban teaching hospital in Mozambique J Surg Res 198(2) 340-345 https://doi.org/10.1016/j.jss.2015.04.010 PMID: 25940163 PMCID: 4560971

10. Carrilho C, Fontes F, and Tulsidás S, et al (2018) Cancer incidence in Mozambique in 2015-2016: data from the Maputo Central Hospital Cancer Registry Eur J Cancer Prev https://doi.org/10.1097/CEJ.0000000000000457

11. Miguel F, Conceição AV, and Lopes LV, et al (2014) Establishing of cancer units in low or middle income african countries: Angolan experience-a preliminary report Pan Afr Med J 19 291-299 https://doi.org/10.11604/pami.2014.19.291.5320

12. Are C, Berman RS, and Wyld L, et al (2016) Global curriculum in surgical oncology Ann Surg Oncol 23 1782-1795 https://doi. org/10.1245/s10434-016-5239-7 PMID: 27120187

13. Gruen RL, Pitt V, and Green S, et al (2009) The effect of provider case volume on cancer mortality: systematic review and metaanalysis CA Cancer J Clin 59 192-211 https://doi.org/10.3322/caac.20018 PMID: 19414631

14. Wyld L, Audisio RA, and Poston GJ (2015) The evolution of cancer surgery and future perspectives Nat Rev Clin Oncol 12(2) 115-124 https://doi.org/10.1038/nrclinonc.2014.191

15. Stephens MR, Lewis WG, and Brewster AE, et al (2016) Multidisciplinary team management is associated with improved outcomes after surgery for esophageal cancer Dis Esophagus 19(3) 164-171 https://doi.org/10.1111/j.1442-2050.2006.00559.x

16. Meguid C, Ryan CE, and Edil BH, et al (2015) Establishing a framework for building multidisciplinary programs $J$ Multidiscip Healthc 8 519-526 https://doi.org/10.2147/JMDH.S96415 PMID: 26664132 PMCID: 4671763

17. Taylor C, Shewbridge A, and Harris J, et al (2013) Benefits of multidisciplinary teamwork in the management of breast cancer Breast Cancer 5 79-85 PMID: 24648761 PMCID: $\underline{3929250}$

18. Hsu YH, Kung PT, and Wang ST, et al (2016) Improved patient survivals with colorectal cancer under multidisciplinary team care: a nationwide cohort study of 25,766 patients in Taiwan Health Policy 120(6) 674-681 https://doi.org/10.1016/j.healthpol.2016.04.001 PMID: $\underline{27131976}$

19. Stefan DC, Masalu N, and Ngendahayo L, et al (2015) Pathology and oncology in Africa: education and training for the future in cancer research—East African Regional Meeting Infect Agent Cancer 10 48-55 https://doi.org/10.1186/s13027-015-0044-7

20. Are C, Malik M, and Patel A, et al (2015) The training and certification of surgical oncologists globally Ann Surg Oncol 22(3) 710-718 https://doi.org/10.1245/s10434-014-4343-9 PMID: 25605512

21. Lopez MS, Baker ES, and Milbourne AM, et al (2016) Project ECHO: a telementoring program for cervical cancer prevention and treatment in low-resource settings $J$ Glob Oncol 3(5) 658-665 https://doi.org/10.1200/JG0.2016.005504

22. Lopez MS, Baker ES, and Schmeler KM, et al (2017) Building a comprehensive cancer education program to increase clinical capacity in Mozambique Meeting Proc J Glob Oncol 22s-23s https://doi.org/10.1200/JG0.2017.009589

23. Lara-Santos S (2017) Take home message: PALOP School of oncology it's a need AORTIC 2017|KIGALI|7-10 NOVEMBER; 283 [http://aorticconference.org/wp-content/uploads/2017/10/2017-AORTICAbstracts.pdf] Date accessed: 16/03/18

24. ten Cate $O$ (2018) A primer on entrustable professional activities Korean J Med Educ 30(1) 1-10 https://doi.org/10.3946/ kjme.2018.76

25. Grover S, Balogun OD, and Yamoah K, et al (2015) Training global oncologists: addressing the global cancer control problem Front Oncol 580 https://doi.org/10.3389/fonc.2015.00080 PMID: 25905040 PMCID: 4389376 